\title{
A Quality Financial Report: Concept Paper
}

\author{
Dumisani Rumbidzai Muzira $^{1}$ \\ ${ }^{1}$ Solusi University, Bulawayo, Zimbabwe \\ Correspondence: Dumisani Rumbidzai Muzira, Solusi University, Bulawayo, Zimbabwe. \\ Email: rdmuzira@gmail.com
}

Received: January 10, $2019 \quad$ Accepted: February 23, $2019 \quad$ Online Published: March 1, 2019

doi: 10.23918/ijsses.v5i3p167

\begin{abstract}
Investors having lost their investments due to misrepresentation of information in financial reports, there is need for continued research on what constitutes a quality financial report. A quality financial report should be able to meet its primary objective of providing relevant information for economic decision making (International Accounting Standard Board Framework). A conceptual framework on a quality financial report is then proposed. This paper therefore seeks to explain the concept of a quality financial report by identifying the financial report's attributes, its antecedences and its outcomes. In order to be useful, the financial report should possess both fundamental and enhancing qualitative characteristics (International Accounting Standard Board Framework). Another attribute, mechanical presentation of the report is then added. The elements considered here being, readability, legibility and report length. The conceptual framework will guide the preparers of financial reports on what constitutes a quality financial report so as to improve their reporting. It will also help the users of financial reports in determining the quality of financial reports before using them for decision making. If this framework of a quality financial report is adopted, there might be a reduction of the occurrences of financial statements scandals and thereby restoring investor confidence in the financial reports.
\end{abstract}

Keywords: Stakeholder Theory, Stewardship Theory, Quality Financial Report, Readability, Legibility

\section{Introduction}

Having lost their investments due to misrepresentation of information in financial reports, investors are demanding quality financial reports with more disclosure. Although quality is subjective, this paper operationalize financial report quality in terms of fundamental qualitative characteristics (relevancy and faithful representation), Enhancing qualitative characteristics (comparability, verifiability, timeliness and understandability) and mechanical presentation characteristics (readability, legibility and report length). A quality financial report is therefore identified using its antecedences, its attributes and its outcomes. The attributes of the financial reports are the ones which makes a distinction between a good quality and a poor quality report.

The purpose of financial statements will also help in the search for a quality financial report. The International Accounting Standard Board (IASB) states the main purpose of financial statements as that of providing information about the financial position, performance and changes in the financial positions of an enterprise that is useful to a wide range of users in making economic decisions (See Deloitte, 2010). Quality being defined as "meeting the customer requirements" or "fitness for purpose or use" (Oakland, 2004, p.5), a quality financial report should therefore meet the requirements of its customers 
who include, the shareholders, the investors, the creditors and the regulators. It should also be fit for the purpose of providing the users with the relevant information for decision making.

\subsection{Background of the Study}

The occurrences of financial statement scandals such as the Enron case and WorldCom made investors lose their confidence in financial reports. Several reporting concepts have been developed in order to meet the financial statement users' ever increasing demand for more information disclosure in financial reports (Beest, Braam, \& Boelens, 2009). These include Corporate Social Responsibility reporting (CSR), environmental reporting, sustainability reporting and integrated reporting. All these reports have to meet certain characteristics for them to be quality reports. This concept paper then offers the characteristics of a quality financial report.

The collapse of big companies like Enron, WorldCom, Tyco international, Waste Management, Freddie Mac, American Insurance Group (AIG), after having produced a series of 'good financial results' left stakeholders questioning whether financial results are adequate as a measure of performance (Thomas, 2002). Did the above organizations' financial reports reflect the 'true and fair' view of the respective organizations? this became the big question (Eccles \& Saltzman, 2011). The need for a framework to guide the companies in what constitutes a quality financial report then sufficed.

\subsection{Problem Statement}

Quality financial reports are to give a 'true and fair view' of the company's operating position for economic decision making (International Accounting Standard Board Framework). 'True and fair view' suggesting that the information revealed in financial reports are free from error and without bias. Dobkowski-Joy and Brockland (2013), Radu-Dan, (2015) are also of the opinion that financial reports should not be just a summation of information, but a compilation of relevant and material information to meet the full disclosure requirements. Quality financial reports should therefore reduce information asymmetry (Nwaobia, Kwarbai, Jayeoba, \& Ajibade, 2016). A quality financial reports should be able to meet the International Financial Reporting standards (IFRS) or the Generally Acceptable Accounting Principles (GAAP) thereby deserving an unqualified opinion from the auditors. In summary, all the fundamental qualitative characteristics, and all the enhancing qualitative characteristics complemented by the mechanical presentations of the report should be met for good quality financial reports.

Despite many companies claiming that their financial reports meet the International Financial Reporting standards, investor confidence in these reports has declined due to the poor quality of reports (Zainudin, \& Hashim, 2016). Lawsuit related to financial reporting are on the increase (Harvard Business Review, July August 2001 issue). Managers even device ways to manipulate the numbers by manipulating operations and not reports (Harvard Business Review, July - August 2016 issue). In their study, Wang and $\mathrm{Wu}$ (2011) had almost 300 companies which amounts to about $2 \%$ of USA listed companies reinstate their previous financial reports in 2005 thereby affecting investor confidence in financial reports. Reinstatement of financial statements is an indication of poor quality in financial reports. The Enron case is another example of poor quality financial statements since the statements were misleading to the decision makers. 
If companies continue to produce poor quality financial reports, investors' confidence in these reports will continue to decline and more companies will continue to restate their financial statements (Wang \& $\mathrm{Wu}, 2011)$. Since studies have shown that the quality of financial reports are inversely related to investment risk (Tang, Chen, \& Lin, 2016), this therefore means that if the quality of financial reports does not improve, investment risk will continue increasing which is not good for the financial markets.

This paper's aim is to propose a conceptual framework for a quality financial report. This will assist the preparers of financial reports in ensuring that their reports have all the attributes of a quality financial reports before presenting them to the users. It will also help the users of financial reports such as the shareholders, the investors, the creditors and the regulators in evaluating the quality of financial reports before they use them for decision making. If both the preparers and the users of financial reports have the same guideline for a quality financial report, users' needs are most likely to be met and thereby boosting users' confidence in financial reports. Quality financial reports will therefore enhance informed decision making by the users which is good for the capital market as investors base their decisions on them.

\subsection{The Gap in Research}

Literature on financial reporting mentions a series of research gaps which include; analysis of factors which may significantly affect quality of internet financial disclosures, the potential indirect impact of internal governance on the extent of voluntary disclosure, factors that impact on the quality of sustainability reports, and exploring the relationship between corporate governance and quality of forward-looking information by using a longitudinal approach and the assessment of the quality of financial reporting (Wang \& Wu, 2011; Chakroun \& Matoussi, 2012; Habek \& Wokniak, 2015; Wen, Mong, Liu, Wise, \& Carey, 2015; Beest, Braam, \& Boelens, 2009). Studies done by Tang, Chen, and Lin (2016) and Wang and Wu (2011) on quality financial reporting focused on country level financial reporting while Dyczkowska, (2014)'s study focused on internet reporting yet other studies such as Filipovic (2012); Beest, Braam, and Boelens (2009) and Kythreotis (2014) were a comparison of the different frameworks for financial reporting. Other studies also focused on a single element such as disclosure, revenue recognition, corporate governance, and financial reporting standards and their relationship to quality reporting (Yurisandi, \& Puspitasari, 2015; Sherman \& Young, 2016; Chakroun, \& Matoussi, 2012; Wen, Mong, Liu, Wise, \& Carey, 2015; Bach, 2016). Since assessment of the quality of financial reports was a recurring concern, it then prompted the researcher to study what constitutes a quality financial report. The proposed framework could be applied to different countries and it encompasses additional elements that have to do with the mechanical presentation of the report which to the best of my knowledge were not covered in previous studies. The assumption being that, if the suggested attributes for a quality financial report are met, then chances of companies producing quality reports would increase. A model is then proposed for the characteristics of a quality financial report.

Literature review was used to come up with the antecedences, the attributes and the outcomes of a quality financial report. Conclusion and recommendations are then drawn from the discussed attributes. This concept paper is intended to benefit the preparers of financial reports, the shareholders, investors, creditors and the regulators in the identification of quality financial reports they might use in making 
informed decisions. It will also help investors and their representatives on corporate boards spot misleading financial reports in time before they lose their investments.

\section{A Quality Financial Report}

A quality financial report concept's theoretical support is from the stewardship theory and the stakeholder theory. Preparers of financial reports should be good stewards that produce quality reports that are relevant for decision making and faithfully represent what has actually occurred without bias, complete and free from error. Information revealed in quality financial reports should provide true and fair information about underlying financial positions and economic performance (FASB, IASB). These quality financial reports should be able to meet the different stakeholder' requirements/needs. The mechanical presentation of the report should also enhance the quality of the report itself. The conceptual framework for a quality financial report is then developed with the antecedents of a quality financial report, its attributes, and outcomes.

\subsection{Antecedents of a Quality Financial Report}

The antecedent conditions that have an influence on a quality financial report are; the guiding accounting standards, the report's intended users and the report preparer's motives. Each antecedent will be briefly described.

\subsection{The Guiding Accounting Standards}

"Different accounting standards may lead to differences in financial reporting and its quality even with the same financial data" (Nijam, \& Jahfer, 2016, p.93). The conventional and generally held wisdom is that the adoption of IFRS lead to financial reporting quality and comparability resulting in favorable economic consequences (Nijam, \& Jahfer, 2016). For United States of America companies, a quality report is guided by the Generally Acceptable Accounting Principles (GAAP) while for other states outside America a quality report is guided by the International Financial Reporting Standards (IFRS). The GAAP and the IFRS offer guidelines and rules to be followed by the preparers of financial reports. There is however a move to converge the GAAP and IFRS. Moreover, various legislation and regulation such as the Sarbanes Oxley Act also strengthen the quality of the financial reports. The guiding accounting standards in each jurisdiction therefore has an influence on what constitutes a quality financial report in that jurisdiction.

\subsubsection{The Report's Intended Users}

Quality is subjective hence different users have different perceptions on what constitutes a quality financial report. For instance, to the environmentalist, a quality report would be expected to report on the companies' impact to the environment while to the investor, a quality report would be expected to report on the economic activities of the organization. The report's intended users will therefore influence what constitutes a quality financial report. 


\subsubsection{The Report Preparer's Motive}

Differences in the quality of financial reports at firm level are heavily influenced by management motivation (Tang, Chen, \& Lin, 2016). Since the preparer of the financial report has the potential of omitting or adding certain information in the financial report in order to meet their desired motives, they then have an influence on the quality of report they produce. Although the preparers of financial reports are expected to disclose all relevant and material information for decision making (IASB Framework), some unethical ones manipulate the information they disclose. This is done by either manipulating the figures to overstate or understate certain transactions or by omitting some relevant information necessary for decision making or even putting too much information that is less useful hence disclosure overload (Ernst \& Young, 2012). These scenarios therefore indicate that the report preparer's motive has an influence on the considerations for a quality financial report.

\subsection{The Attributes of a Quality Financial Report}

There are certain attributes that are associated with a quality financial report such as relevance, faithful representation, comparability, verifiability, timeliness, and understandability (IASB framework, 2008). Other studies have accessibility, accuracy, appropriateness, clarity, compliance with standards, comparability, completeness, consistency, costs, duration, familiarity, frequency, language, punctuality, relevance, timeliness, transparency, unambiguity and usability as attributes of a quality report (Nederpelt, 2011). In addition to these attributes, this paper adds on mechanical presentation characteristics such as readability, legibility and report length to the list of attributes. A quality report should then be able to meet its users' needs and should also fulfill its purpose. The users need full disclosure of relevant material information for economic decision making while the purpose of financial reports is to provide the users with such information. In this study, the attributes of a quality financial report are put into three categories which are; fundamental qualitative characteristics, enhancing qualitative characteristics and the report's mechanical presentation as explained below.

\subsubsection{Fundamental qualitative characteristics}

The fundamental qualitative characteristics, relevance and faithful representation are the most important and determine the content of financial reporting information (Beest, Braam \& Boelens, 2009). Relevance referring to the capability "of making a difference in the decisions made by users in their capacity as capital providers" (IASB, 2008, p. 35). Relevance is then operationalised by two elements; predictive and confirmatory. Relevant information should therefore confirm the past and also be helpful for users to predict the future.

The second fundamental qualitative characteristic, faithful representation is explained by three elements; complete, neutral and free from error. Complete meaning that the report presents all the necessary information since omission of information can lead to mislead decisions. Neutral meaning the information in the financial report is not biased. Free from error does not mean 100 percent correct since this is difficult to attain with some of the financial information being based on estimates. However, for financial reports to be considered free from error in an uncertain environment, full disclosure is necessary (IASB, 2008). 


\subsubsection{Enhancing Qualitative Characteristics}

Enhancing qualitative characteristics also enhances the usefulness of financial reports for decision making (IASB, 2008). These are operationalised by comparability, verifiability, timeliness and understandability. Comparability aids in trend/longitudinal analysis and cross-sectional analysis of the information presented in financial reports. This helps in evaluating performance of companies over different accounting periods and also performance in comparison to the other companies within the same industry. Comparability however need similar application of accounting policies over a period of time (IASB, 2008).

Verifiability, enhances usefulness for decision making in that, the financial reports would be free from error and unbiased (GAAS). If different auditors would look at the same information independently, they would get to the same conclusion about its truthfulness. Verifiability therefore helps in assuring the users that the financial reports are a true representation of the underlying transactions, hence quality in reporting.

The third element, timeliness refers to the need for accounting information to be presented to the users in time in order for it to influence the decision making. Even if accurate, reliable information is released after the date a decision has been made, it becomes useless for decision making because it will be difficult to change the tables once a decision has already been made. This therefore means that timeliness of information is useful for it to influence decision making.

The last element understandability has to do with the users comprehending the information in the financial report. "Understandability will increase when information is classified, characterized and presented clearly and concisely" (Beest, Braam \& Boelens, 2009, p. 14). The same authors are of the view that financial reports should be presented in a well-organized manner with the use of tables and graphs where necessary to enhance understandability. A quality financial report should therefore be understandable for the users to act on the information presented. However, understandability largely depends on the user's level of knowledge of business and economic activities (IASB, 2008).

\subsubsection{Report's Mechanical Presentation}

In addition to the IASB's fundamental qualitative characteristics and enhancing qualitative characteristics for a quality financial report, this paper proposes the report's mechanical presentation as another category for the attributes of a quality financial report. This came after realizing that it is not just the content of the report that makes it a good one, how the information is presented to the users is of vital importance too. In order to ensure that the reported information gets to the intended users in the best format, the mechanical presentation is operationalized by; readability, legibility and report length.

Readability refers to the ease with which a reader can understand the written report (DuBay, 2004). It enhances clarity and is determined by the vocabulary load, reading grade level, spacing of letters, words and lines. The guidelines for readability are:

- Use short, simple, familiar words

- Avoid jargon. 
- Use culture-and-gender-neutral language.

- Use correct grammar, punctuation, and spelling.

- Use simple sentences, active voice, and present tense.

- Begin instructions in the imperative mode by starting sentences with an action verb.

- Use simple graphic elements such as bulleted lists and numbered steps to make information visually accessible (DuBay, 2004, p.2).

The same author observed that when texts exceed the reading ability of the readers they usually stop reading. This therefore makes readability one of the attributes for a quality report in that, if the readers cannot read it with ease, they might stop reading the report altogether and hence make uninformed decisions.

The second attribute, legibility refers to how easy it is to distinguish one letter from another in a particular typeface (DuBay, 2004). The elements of legibility being the layout are, the typeface and the font size used for the financial report. For legibility to be enhanced, the typeface, layout and font size used should not be distractive by drawing the reader's attention to it rather than to the information being presented. This therefore makes legibility an attribute for a quality financial report.

Lastly, the length of the report matters in determining a quality financial report. Despite the costs associated with providing more information, information overload can be experienced and it can obscure important information that is useful for decision making. Reading lengthy reports can be wearisome to the readers causing them to fail to read the full report hence missing some information that could be useful for decision making. Reports that are too short might not be good either, as they might leave out some important information for decision making. A balance should therefore be made by ensuring that all the relevant material information for decision making has been reported in a concise manner.

\subsection{The Outcomes of a Quality Financial Report}

A quality financial report should be able to meet the objectives of it being prepared. If a financial report has provided the users with all the relevant material information for decision making, they have fulfilled the objectives that led to them being prepared. A quality financial report should therefore give a strong basis for decision making by external users, internal users and the regulators.

\subsubsection{Decision Making Basis by External Users}

A quality financial report forms the basis for decision making by external users. These external users include the investors, the creditors, banks, and potential investors. The investors and potential investors rely on financial reports in evaluating past performance and the organization's future prospects. The creditors and the banks would need to know the financial position of the organization for them to make a decision of extending the credit to the organization after assessing the ability of the organization to repay its obligation. Since each of these users make decisions based on the information revealed in the financial reports, there is need for quality financial reports to avoid misled decision making. 


\subsubsection{Decision Making Basis by Internal Users}

A quality financial report also helps internal users such as the shareholders, the managers and the employees in their decision making. The shareholders would use information in financial reports to evaluate the performance of the organization, the performance of the managers and their return on investment. The managers would also use the information in financial reports in making decisions on production levels, sales levels and budgetary issues. The employees can also use information in financial reports to determine if their organization will be able to remunerate them, whether it is will continue operating in the long-run and whether it will be able to offer them bonuses and salary increments in the future. Quality financial reports will therefore be useful for the internal users in making informed decisions for their personal benefit and the benefit of the organization at large.

\subsubsection{Decision Making Basis by the Regulators}

Finally, the regulators such as the government and the stock exchange also base some of their decisions from the financial reports hence the need for them to be of a quality nature. These decisions include taxation decisions by the government, mandatory and voluntary requirements by the stock exchanges and revision of standards by the standard boards. From the financial reports, the regulators can evaluate whether more stiff regulations and increased penalties are needed or not. This therefore makes quality financial reports useful as a base from which the regulators make their decisions.

\section{The Proposed Conceptual Framework for a Quality Financial Report}

Figure 1 below is a proposed conceptual framework for a quality financial report. It shows the antecedent conditions for a quality financial report, its attributes as well as its outcomes. 


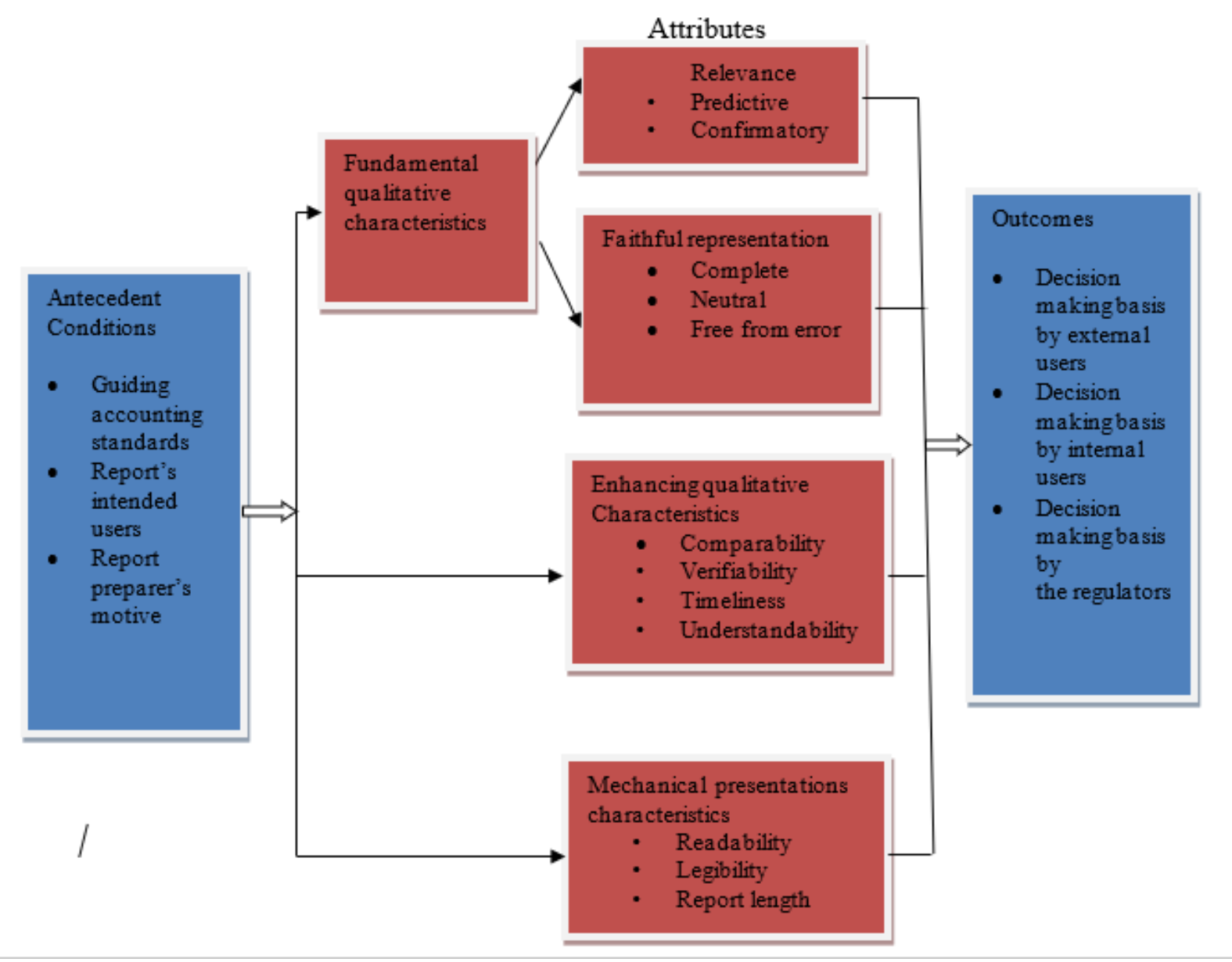

Figure 1: The Proposed Conceptual Framework for a Quality Financial Report

\section{Criticism on the Practicality of a Quality Financial Report}

In an attempt to describe a quality financial report, subjective terms are used. A quality financial report should provide all the relevant material information for decision making. The word 'quality' is subjective. Relevance and materiality is not universal either, it depends on many factors such as where the information is needed, the industry, size of organization, its operations and the internal and external environment it operates from.

With the current move for fair value accounting especially on intangible assets such as goodwill, verifiability will be more difficult to attain than with historical costing (Kaya, 2013). Although verifiability might be affected by fair values, in unstable environments, fair values would be more realistic than historical costs. This therefore means that the attributes for a quality financial reports should not be considered in isolation, they are inter-related and therefore complement each other. 


\subsection{Conclusion}

Although there is no common definition for quality, many authors agree that quality has to do with meeting the customers' needs, and being fit for the purpose intended (Oakland, 2004). The attributes of a quality financial report discussed in this paper are therefore an effort to help the preparers of financial reports meet the report users' needs and also help them fulfill the major purpose of financial reports thus aiding in economic decision making. The issue of materiality is however left to each organization to decide considering the uniqueness of each organization with regards to its size, its operations and the environment it operates from. If the preparers of financial report consider all the antecedences, attributes and outcomes of a quality financial report, it would guide them in producing one. The production of quality financial reports would then lead to informed decision making by the users and therefore increase their confidence in financial reports.

\subsection{Recommendation}

In a business world that has financial statements fraud and scandals, a conceptual framework for a quality financial report might be useful. Businesses face the ever-changing environment, yet the financial reports still form a basis for decision making both internally and externally. A recommendation is then made that continuous research on the attributes of a quality financial report be done. These would assist in the adjustments of the proposed conceptual framework to help solve the imaging challenges.

\section{References}

Bach, L. T. (2016). The impact of financial statement disclosure on conservatism in financial reporting: Evidence from Vietnam. International Journal of Economics and Financial Issues, 6(6) 158161.

Beest, F. V., Braam, G., \& Boelens, S. (2009). Quality of financial reporting: Measuring qualitative characteristics. Nijmegen Center of Economics working Paper 09-108. Retrieved from http://www.ru.nl/nice/workingpapers

Chakroun, R.\& Matoussi, H. (2012), Determinants of the extent of voluntary disclosure in the annual reports of the Tunisian firms. Accounting and Management Information Systems 11( 3), 335370

Dobkowski-Joy, A., \& Brockland, B. (2013). The state of integrated reporting: Innovation and experimentation in the merging of ESG and financial disclosure (The State of Integrated Reportingframework-llc.com). Retrieved fromhttp://framework-llc.com/wpcontent/uploads/2013/03/FrameworkLLC _StateOfIntegratedReporting_0313.pdf

DuBay, W. H. (2004). The principles of readability. Retrieved from http://en.copian.ca/library/research/readab/readab.pdf

Dyczkowska, J. (2014). Assessment of quality of internet financial disclosures using a scoring system: A case of Polish stock issuers. Accounting and Management Information Systems, 13(1), 50-81

Eccles, R. G., \& Saltzman, D. (2011). Achieving sustainability through integrated reporting. Stanford Social Innovation Review. Retrieved from http://environment.harvard.edu/sites/default/files/2011SU_Features_EcclesSaltzman.pdf

Ernst \& Young. (2012). Now is the time to address disclosure overload. Retrieved from http://www.ey.com/Publication/vwLUAssets/ToThePoint_BB2367

_DisclosureOverload_21June2012/\$FILE/TothePoint_BB2367_DisclosureOverload_21June20 12.pdf 
Filipovic, A. L. (2012). Revised qualitative characteristic of financial statements as precondition for strengthening information power on capital market.

Economics and Organization 9(1), 81 - 92 retrieved from http://facta.junis.ni.ac.rs/eao/eao201201/eao201201-07.pdf

Kaya, T. C. (2013). Fair Value versus Historical Cost: Which is actually more "Fair"? The Journal of Accounting and Finance. Retrieved from http://www.journal.mufad.org/attachments/article/717/8.pdf

Kythreotis, A. (2014). Measurement of financial reporting quality based on IFRS conceptual framework's fundamental qualitative characteristic. European Journal of Accounting, Finance and Business, 2(3), 4-29.

Habek, P. \& Wokniak, R. (2015). Assessing the quality of corporate social responsibility reports: The case of reporting practices in selected European Union member states. Quality \& Quantity, 50, 399-420.

IASB (2008). Exposure draft of an improved conceptual framework for financial reporting: The objective of financial reporting and qualitative characteristics of decision-useful financial reporting information. Retrieved from

http://www.assb.gov.sg/docs/attachments/EDofChapters1and2theJointImprovedConceptualFra mework.pdf

Nederpelt, P. V. (2011). Attributes of quality reports. Retrieved from http://www.oqrm.org/English/2011_Attributes_of_quality_reports.pdf

Radu-Dan, T. (2015). Integrated reporting: The next step ahead for a sustainability society. European Journal of Business Science and Technology, 1(1), 64-75. Retrieved from https://www.ejobsat.cz/wp-content/uploads/2015/10 /EJOBSAT150101_004.pdf

Sherman, D. H. \& Young, D. S. (2016). Where financial reporting still falls short. Harvard Business Review, July -August 2016 issue, pp. 76-84

Tang, Q. Chen, H. \& Lin, Z (2016). How to measure country-level financial reporting quality? Journal of Financial Reporting and Accounting, 14 (2), 230-265

Thomas, W. C. (2002). The rise and fall of Enron: When a company looks too good to be true, it usually is. Journal of Accountancy. Retrieved from http://www .journalofaccountancy.com/issues/2002/apr/theriseandfallofenron.html

Wang, X. \& Wu, M. (2011).The quality of financial reporting in China: An examination from an accounting restatement perspective. China Journal of Accounting Research, 4(4), 167-196

Wen, Q., Mong, S. E., Liu, L., Wise, V., Carey, P. (2015). Corporate governance and quality of forward-looking information Evidence from the Chinese stock market. Asian Review of Accounting 23 ( 1), 39-67

Yurisandi, T. \& Puspitasari, E. (2015). Financial reporting quality-Before and after IFRS adoption using NiCE qualitative characteristics measurement. Paper presented at the $2^{\text {nd }}$ Global Conference on Business and Social Sciences, Bali, Indonesia, September 17-18, 2015. Retrieved from http://ac.els-cdn.com /S1877042815054312/1-s2.0-S1877042815054312-main.pdf?_tid=f9c747fc-5a3e-11e7-929100000aacb35e\&acdnat $=1498461398$ _f8a5be111e31f7ee8fb3e31537426142

Zainudin, E. F., \& Hashim, H. A. (2016). Detecting fraudulent financial reporting using financial ratio. Journal of Financial Reporting and Accounting, 14 (2). 